\title{
Unravelling rhetoric
}

Alison Williams \& Derek Jones

There is a French phrase for that frustrating feeling you have upon realising what you should or could have said in a conversation: l'esprit d'escalier or 'staircase wit'. Very often you may (after the event, of course, on the way down the stairs) think of several things you could have said - each of which is most likely exceptionally witty and erudite. This feeling may go on for hours or even days, a constant replay of events with an ever-increasing list of Things I Should Have Said But Didn't.

But being able to respond quickly and confidently in the spur of the moment can be difficult - especially when responding to someone who appears exceptionally confident in what they are stating and the rhetoric they are using. The word rhetoric is important here because it is often this that convinces quickly rather than facts, information or critical dialogue. This is not to say that all rhetoric is a bad thing - we all use it. It's simply that it can do with a health check every now and again.

This recipe is not about giving the confidence or repartee to retort in any situation. It's about recognising some of the most common rhetorical devices used in place of knowledge - where opinion is very often passed off as knowledge and winning an argument is more important than exploring an issue.
By the way, we all do this. Humans are exceptional at 'lazy epistemology'. In other words, we don't have the energy to spend on thinking about everything all the time so we take shortcuts. And if those shortcuts get too short, we end up missing or distorting things.

So try this recipe as a grounded observational method the next time you find yourself in such a situation - keep an eye out: to ensure that opinion is not passed off as fact, and to ensure that ideas and thoughts are explored, not dismissed.

\section{Ingredients}

- Smile and pause.

- A few holding phrases.

- Carl Sagan's Baloney Detection Kit (Sagan, 1996). https://www. brainpickings.org/2014/01/03/ baloney-detection-kit-carl-sagan/

- A copy of the Thou Shalt Not Commit Logical Fallacies poster (Richardson, 2012).

\section{Method}

1. When you are confronted with that horrible situation of feeling the need to respond, think: "Do I have to respond at all?" Not everything demands an immediate response. Quickly scan the type of conversation it has been so far - if you count mostly Sagan 'baloney statements' then you 
might want to think about whether there is any point in continuing.

Look especially for the following:

- points that attack the person, not the argument or critique;

- argument that relies only on authority;

- extreme dualities and failure to recognise complexity (e.g. "You are either for this position or you're not");

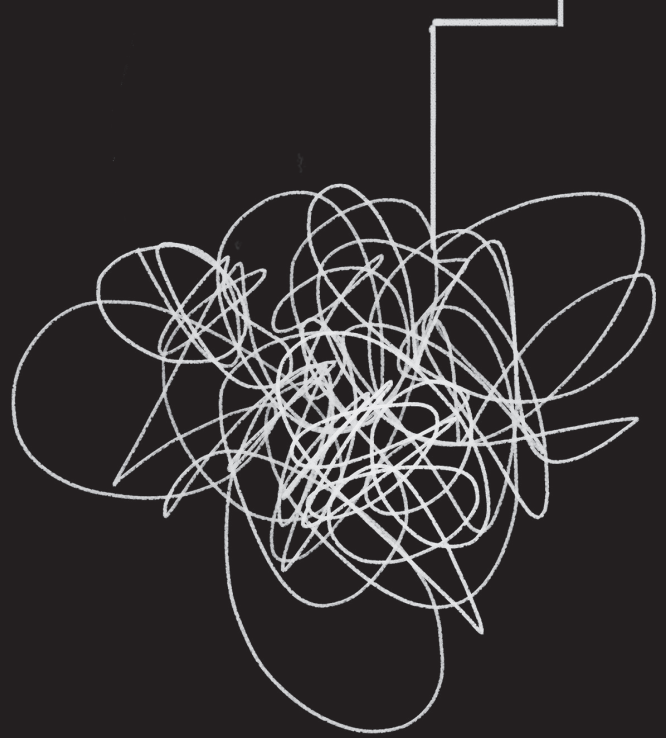

- following quickly after a duality, some statement invoking 'normal', 'most' or 'average' people. Remember, 'normal' is simply a measure of statistical distribution of how far EVERYONE is away from an unattainable mathematical ideal;

metaphorical arguments that assume a knowledge that is not necessarily valid (e.g. "We have to cut off this limb to save the patient");

- memes that may be compelling for no other reason than the perceptual appeal (e.g. "Better dead than red");

- lazy dismissal: "Oh that's just...", "Don't be like that...", "I was only...". 
2. Have a few holding phrases you can use in situations where it is clear that rhetoric, not content, is being valued. For example:

- "I think this issue would really benefit from..."

- "An unusual point of view, I would like to ponder this at leisure..."

- "Let me get back to you on this..."

- "Mmm...interesting..."

3. Ask critical and rational questions (from Sagan's toolkit):

- " "Is there research into this?"

- "What other ideas are there supported by the same evidence?"

- "Has anyone considered this issue from the point of view of $X$ ?"

- Ask a quantitative question: "How many...?", "How much...?", "When does...?"

4. You do not have to adopt the same pace, pitch and intensity of discussion as your discussant.

- If you wish to talk slowly in response to someone talking too quickly then do that - if an idea is strong it will benefit from a measured and considered speed of consideration.

- Talking quietly can be more effective than increasing volume.
- Ifyou are interrupted without consideration or with disrespect, turn your body away slightly - show your shoulder. This can interrupt the interruption.

- Ifyou are repeatedly interrupted then remember that you have already 'left' the conversation - it's OK to walk away from your time being wasted.

5. Remember that certain types of persuasion rely on drawing a discussant into the rhetoric itself, e.g. by making them appear a certain way or using their reaction as 'evidence' of something. As part of any conversation you should feel able to withdraw at any time - that's what discussion is. You may need a couple of phrases, rather than just: "Oh goodness, is that the time, I must fly, I can't keep [Nobel Prize-winner as appropriate] waiting any longer!" Adapt the holding phrases above to suit, or say that you are feeling...

- that this discussion has turned rhetorical and is no longer exploratory;

- that the discussion has reached an unhelpful circularity;

- browbeaten. 